\title{
Transformational Leadership Senior Assistant Co- curriculum: The Relationship between Perspectives and Satisfaction Among Secondary School Sports and Games Club Advisory Teachers
}

\section{Kepimpinan Transformasional Penolong Kanan Kokurikulum: Hubungan antara Perspektif dengan Kepuasan dalam Kalangan Guru Penasihat Kelab Sukan dan Permainan Sekolah Menengah}

\author{
Nguang Ung Siong ${ }^{1 *}$, Lau Siew Hung ${ }^{1}$ \\ ${ }^{1}$ Institut Pendidikan Guru, Kampus Tun Abdul Razak, \\ Kota Samarahan, MALAYSIA \\ *Corresponding Author
}

DOI: https://doi.org/10.30880/jstard.2020.02.03.005

Received 30 September 2020; Accepted 30 November 2020; Available online 31 December 2020

\begin{abstract}
This study was conducted to identify the relationship between the perspective and satisfaction of school sports and games club advisory teachers on the transformational leadership of Senior Assistant Co-curriculum in Secondary schools. This study is a comparative causal study and uses the Group Sampling method involving 550 secondary school teachers in Sarawak. Pearson correlation results $r=.796, p<0.05$ showed that there was a high and significant relationship between the transformational leadership perspective of the Senior Assistant Cocurriculum with satisfaction among secondary school sports advisory teachers. The charismatic dimension has shown the highest relationship to the satisfaction of sports club and game club advisors and is followed by the dimension of intellectual stimulation as well as inspirational motivation. The dimension of individual judgment has shown the lowest relationship to the satisfaction of sports and game club advisory teachers. Nevertheless, the dimension of individual judgment still has a high relationship with the satisfaction of sports clubs and game club advisors. Thus, transformational leadership is proposed to the Senior Assistant Co-curriculum in secondary schools because it can influence the level of satisfaction of sports club and game club advisors in the implementation of sports activities to achieve school goals and goals.
\end{abstract}

Keywords: Transformational leadership, perspective, satisfaction, teacher advisor 


\begin{abstract}
Abstrak: Kajian ini dijalankan untuk mengenalpasti hubungan antara persepktif dan kepuasan guru penasihat kelab sukan dan permainan sekolah terhadap kepimpinan transformsional Penolong Kanan Kokurikulum di sekolah Menengah. kajian ini berbentuk kajian causal comparative dan menggunakan kaedah Persampelan Berkelompok yang melibatkan 550 orang guru sekolah menengah di Sarawak. Keputusan korelasi Pearson r=.796, sig $<0.05$ telah menunjukkan terdapat hubungan yang tinggi dan signifikan antara perspektif kepimpinan transformasional Penolong kanan Kokurikulum dengan kepuasan di kalangan guru-guru penasihat sukan sekolah menengah. Justeru, kepimpinan transformasional dicadangkan kepada Penolong Kanan Kokurikulum di sekolah menengah kerana mampu mempengaruhi tahap kepuasan guru penasihat kelab sukan dan permainan dalam pelaksanaan aktiviti-aktiviti sukan demi mencapai sasaran dan matlamat sekolah
\end{abstract}

Kata Kunci: Kepimpinan transformasional, persepktif, kepuasan, guru penasihat

\title{
1. Pengenalan
}

Pengurusan sukan di sekolah adalah penting untuk menyokong dan mencapai matlamat dasar satu murid satu sukan (KPM, 2011); mengecapi kecemerlangan sukan dan kokurikulum di sekolah selaras dengan Falsafah Pendidikan Kebangsaan (FPK) untuk melahirkan pelajar yang seimbang dan harmonis dari segi jasmani, emosi, rohani, dan intelek (KPM, 2012). Justeru, kepimpinan dalam bidang pengurusan sukan menjadi semakin mencabar terhadap pemimpin sekolah terutamanya Penolong Kanan Kokurikulum yang bertanggungjawab secara langsung dan diberikan amanah untuk memimpin sekolah dalam mencapai kecemerlangan sukan dan kokurikulum. Ini kerana kepimpinan memainkan peranan penting untuk membolehkan seseorang pemimpin dalam mempengaruhi ahli-ahli di bawah pimpinannya bagi bersama-sama mencapai matlamat organisasi (Robbins \& Judge, 2007). Begitu juga dengan kemampuan kepimpinan Penolong Kanan Kokurikulum di sekolah Menengah dalam mempengaruhi guru-guru penasihat sukan dan permainan ke arah mencapai visi dan matlamat sekolah demi mencapai kecemerlangan sukan yang disasarkan. Justeru, kepimpinan transformasional merupakan gaya kepimpinan yang sesuai dengan keperluan pada masa kini untuk membawa transformasi terhadap pengurusan sukan dan permainan dan memberikan impak yang positif terhadap kejayaan sukan dan kokurikulum di sekolah menengah.

Namun begitu, kepuasan guru penasihat kelab sukan dan permainan terhadap gaya kepimpinan pemimpin di sekolah juga penting untuk meningkatkan motivasi mereka dalam melaksanakan tugasan sebagai penasihat kelab sukan dan permainan serta memastikan pelaksanaan program sukan di sekolah dengan berkesan dalam mencapai matlamat dasar satu murid satu sukan dan kecemerlangan sukan sekolah (KPM, 2011). Namun begitu, kepuasan kerja guru menjadi kurang memuaskan apabila kebanyakan guru mengalami tekanan dalam pekerjaan (Cormarks, 2000). Namun begitu, permasalahan ketidakpuasan guru-guru yang membimbangkan ini dapat diatasi dengan amalan kepimpinan transformasional pihak pentadbir sekolah dalam pengurusan dan pelaksanaan aktiviti sukan di sekolah.

\section{Sorotan Karya}

Kajian Tang (2011) mendapati kepimpinan transformasional perlu diberikan perhatian oleh pemimpin-pemimpin di sekolah kerana penggunaan gaya kepimpinan transformasi ini dapat meningkatkan motivasi kerja guru-guru di sekolah melalui dimensi-dimensi kepimpinan transformasional seperti motivasi inspirasi, rangsangan intelek, pertimbangan individu dan karismatik. Apabila diaplikasikan dalam pengurusan sukan oleh penolong kanan kokurikulum, ianya juga dapat memberikan impak positif kepada guru penasihat kelab sukan dan permainan.

Kajian Nazim \& Mahmood (2016) telah mengkaji hubungan kepimpinan transformasional pengetua dengan kepuasan kerja guru kolej di Pakistan. Hasil dapatan kajian telah menunjukkan wujudnya hubungan antara kepimpinan transformasional dengan kepuasan kerja dan terdapat hubungan yang tinggi dan signifikan antara kepimpinan transformasional dengan kepuasan kerja guru kolej di Pakistan. Sementara itu, kajian Arokiasamya, Abdullah \& Zohir (2016) juga telah menunjukkan terdapat hubungan yang signifikan antara kepimpinan transformasional dengan kepuasan kerja guru-guru sekolah rendah di Perak, Malaysia. Dimensi karismatik menunjukkan hubungan yang paling tinggi, diikuti oleh dimensi motivasi inspirasi, rangsangan intelektual dan pertimbangan individu. Justeru, amalan kepimpinan transformasional pengetua perlu berada dalam tahap yang tinggi untuk menjamin kepuasan kerja guru. Ini kerana kepimpinan transformasional merupakan kepimpinan yang mempunyai matlamat dan halatuju yang sistematik serta jelas untuk membantu pemimpin mencapai pengurusan yang berkualiti. Oleh itu, pemimpin yang mengamalkan kepimpinan transformasional ialah pemimpin yang mempunyai wawasan, sentiasa bermotivasi tinggi dan mempunyai matlamat yang jelas.

Kajian Noraazian \& Khalip (2016) juga mengkaji tentang kesan kepimpinan transformasional terhadap komitmen guru di sekolah rendah di Perak, Malaysia. Hasil dapatan kajian juga menunjukkan bahawa kepimpinan transformasional pengetua mempunyai hubungan positif dengan komitmen guru-guru sekolah rendah di Perak. Namun 
begitu, dimensi pertimbangan individu telah menunjukkan hubungan yang paling tinggi, $\mathrm{r}=.901$ dengan komitmen kerja guru, dikuti oleh dimensi motivasi inspirasi, r=.847, karismatik, r=0.847 dan rangsangan intelektual, r=.763. Komitmen yang tinggi ditunjukkan oleh guru-guru apabila mereka amat berpuas hati dengan corak kepimpinan pengetua yang mengutamakan kebolehan individu, menggunakan pengaruh dengan positif, memberi penghargaan terhadap kerja yang baik dan kepercayaan terhadap kemampuan guru di sekolah.

Kajian Kouni, Koutsoukos \& Panta (2018) juga telah menunjukkan bahawa kepimpinan transformasional mempunyai hubungan yang tinggi dan penting dalam memberikan kesan yang positif terhadap kepuasan kerja guruguru di sekolah menengah di Greece. Oleh itu, kepusan kerja guru mampu memberikan kesan yang positif terhadap pencapaian akademik sekolah. Kajian Kouni, Koutsoukos \& Panta (2018) seiring dengan kajian Lyonga (2019) yang juga mendapati terdapat hubungan positif antara kepimpinan transformasional dengan kepuasan kerja guru di sekolah menengah kerana kemahiran kepimpian kepimpinan transformasional pengetua telah meningkatkan kepuasan kerja guru sekolah menengah di Cameroon. Justeru, model kepimpinan transformasional adalah paling sesuai untuk diimplementasikan oleh pentadbir sekolah bagi memimpin guru-guru bagi mencapai matlamat dengan merangsang keperluan guru-guru yang dipimpin pada masa yang sama (Hoy \& Miskel, 2013). Justeru, amalan kepemimpinan transformasi oleh pengetua mampu meningkatkan prestasi guru dan komitmen guru kerana dapat mewujudkan perhubungan kemanusiaan yang lebih tinggi yang memberikan impak positif ke atas kepuasan kerja guru (Kouni, Koutsoukos \& Panta, 2018; Lyonga, 2019). Oleh itu, penolong kanan kokurikulum yang juga memainkan peranan sebagai memimpin di sekolah juga boleh mengamalkan kepimpinan transformasional untuk memastikan kepuasan guru penasihat kelab sukan dan permainan dalam pelaksanaan aktiviti sukan sekolah bagi meningkatkan pencapaian prestasi sukan di sekolah.

\section{Metodologi}

Kajian ini berbentuk kajian causal comparative dan data dikumpul bagi mengenalpasti hubungan antara perspektif dan kepuasan guru penasihat sukan terhadap kepimpinan transformasional penolong kanan kokurikulum (Creswell, 2012; Idris, 2010). Populasi ini terdiri daripada guru-guru penasihat sukan sekolah Menengah di Sarawak. Kaedah persampelan berkelompok (Cluster) digunakan dalam kajian ini di mana kaedah ini adalah berbentuk populasi mudah diurus dan mempunyai ciri yang hampir sama dari sudut fizikal (Babbie, 2001; Newman, 2003). Daripada 31 buah Pejabat Pendidikan Daerah PPD di Sarawak, 5 Pejabat Pendidikan Daerah di Sarawak pilih dan 5 buah sekolah dipilih dalam setiap daerah. Daripada 25 buah sekolah yang dipilih dalam kajian ini, 22 orang guru dipilih secara rawak daripada sekolah yang terlibat dan menjadikan saiz sampel secara keseluruhan adalah sebanyak 550 orang guru.

Instrumen kajian ini adalah borang soal selidik yang diubah suai daripada Multifactor Leadership Questionnaire (Avolio \& Bass, 2004) yang menggunakan skala Likert 5 poin untuk mengukur perspektif dan kepuasan guru penasihat dan terdiri daripada 5 dimensi, iaitu pertimbangan individu, karismatik, motivasi berinspirasi, rangsangan intelektual dan skala kepuasan. Data yang dikutip dan dianalisis dengan menggunakan perisian SPSS versi 25.0.

\section{Dapatan dan Perbincangan}

Jadual 1 - Ujian skweness dan kurtosisi dalam perspektif kepimpinan transformasional dan kepuasan guru

\begin{tabular}{lll}
\hline Aspek & Skewness & Kurtosis \\
\hline Perspektif Kepimpinan Transformasional & -1.340 & -1.028 \\
Kepuasan Guru & -1.423 & -0.932 \\
\hline
\end{tabular}

Dalam Jadual 1, ujian Skewness dan Kurtosis bagi perspektif kepimpinan transformasional Penolong Kanan Kokurikulum dan kepuasan guru-guru sekolah menengah di Sarawak berada di antara \pm 1.96 (Pallant, 2013) dan telah mematuhi kenormalan taburan data. Apabila data adalah bertaburan normal seperti yang ditunjukkan dalam Jadual 1, ujian korelasi Pearson digunakan untuk mengenal pasti hubungan antara perspektif guru penasihat sukan terhadap kepimpinan transformasional Penolong Kanan Kokurikulum dengan kepuasan guru-guru sekolah menengah di Sarawak. 
Jadual 2 - Ujian korelasi bagi perspektif guru penasihat sukan terhadap kepimpinan transformasional dengan kepuasan guru penasihat kelab sukan dan permainan

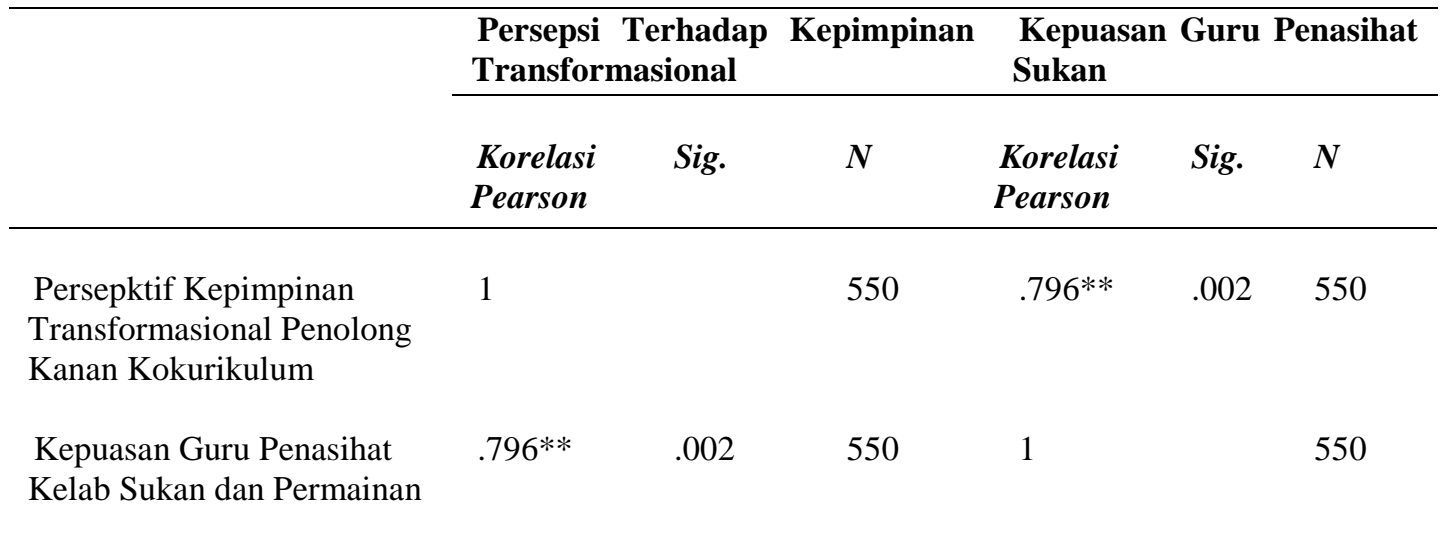

Berdasarkan Jadual 2, nilai korelasi Pearson yang diperolehi adalah $r=.796, p<0.05$. Hasil dapatan ini menunjukkan terdapat hubungan yang signifikan antara perspektif kepimpinan transformasional Penolong kanan Kokurikulum dengan kepuasan guru penasihat sukan di kalangan guru-guru sekolah menengah. Keputusan korelasi Pearson juga menjelaskan terdapat hubungan korelasi yang tinggi antara perspektif kepimpinan transformasional Penolong kanan Kokurikulum dan kepuasan guru penasihat sukan di sekolah menengah di Sarawak. Justeru, kepimpinan transformasional yang diamalkan oleh Penolong Kanan Kokurikulum yang di sekolah menengah mempengaruhi tahap kepuasan guru penasihat kelab sukan dan permainan. Oleh itu, kajian ini menunjukkan bahawa kepimpinan transformasional merupakan faktor penting untuk menjamin kepuasan guru penasihat kelab sukan dan permainan dalam melaksanakan aktiviti-aktiviti sukan di sekolah menengah demi mencapai sasaran dan matlamat sekolah yang ditetapkan oleh Penolong Kanan Kokurikulum.

Jadual 3 - Ujian korelasi dimensi-dimensi kepimpinan transformasional dengan kepuasan guru penasihat kelab sukan dan permainan

\begin{tabular}{lcc}
\hline Dimensi Kepimpinan Transformasional & Kepuasan & $\mathrm{r}$ \\
\hline Karismatik & Korelasi Pearson (2-tailed) & .862 \\
\hline Rangsangan Intelek & Korelasi Pearson (2-tailed) & .823 \\
\hline Motivasi Inspirasi & Korelasi Pearson (2-tailed) & .784 \\
\hline Pertimbangan Individu & & .715 \\
\hline
\end{tabular}

Berdasarkan Jadual 3, nilai korelasi Pearson untuk dimensi karismatik dan tahap kepuasan guru adalah r=.862 dan dimensi karismatik merupakan dimensi kepimpinan transformasional yang mempunyai hubungan yang paling tinggi terhadap kepuasan guru penasihat kelab sukan dan permainan. Seterusnya diikuti oleh dimensi rangsangan intelek, $\mathrm{r}=.823$ dan motivasi Inspirasi, $\mathrm{r}=.784$ seperti yang ditunjukkan dalam Jadual 3. Sementara itu, dimensi pertimbangan individu mempunyai hubungan yang paling rendah berbanding dimensi-dimensi lain terhadap kepuasan guru penasihat kelab sukan dan permainan dengan nilai korelasi Pearson $\mathrm{r}=.715$. Namun begitu, hubungan dimensi pertimbangan individu masih menunjukkan hubungan yang tinggi dengan kepuasan guru penasihat kelab sukan dan permainan.

Kajian ini telah menunjukkan bahawa amalan kepimpinan transformasi adalah penting untuk membantu penolong kanan kokurikulum dalam pengurusan sukan dan membimbing guru penasihat kelab sukan dan permainan kerana mempunyai hubungan yang tinggi dengan kepuasan kerja guru di sekolah menengah. Kajian ini seiring dengan kajian Nazim \& Mahmood (2016) dan kajian Arokiasamy, Abdullah \& Zohir (2016) yang juga menunjukkan hubungan tinggi antara amalan kepemimpinan transformasi pentadbir dengan kepuasan kerja guru- guru di kolej dan di sekolah rendah. Selain di sekolah rendah dan kolej, kajian ini membuktikan kepimpinan transformasional juga sesuai diamalkan oleh pentabir di sekolah menengah.

Dapatan ini juga selaras dengan kajian Kouni, Koutsoukos \& Panta (2018) dan kajian Lyonga (2019) di mana amalan kepimpinan transformasional juga memberikan pengaruh positif terhadap kepuasan kerja untuk guru-guru di sekolah menengah kerana kepuasan guru di sekolah menengah adalah dipengaruhi oleh gaya kepimpinan pentadbir sekolah. Justeru, dimensi-dimensi kepimpinan transformasional seperti pertimbangan individu, motivasi inspirasi, 
rangsangan intelektual dan karismatik mempunyai hubungan tinggi terhadap kepuasan guru penasihat sukan dan permainan di sekolah (Tang, 2011; Noraazian \& Khalip, 2016). Oleh itu, guru-guru akan mempunyai kepuasan yang tinggi dalam melaksanakan amanah yang diberikan untuk melaksanakan aktiviti kelab sukan dan permainan apabila penolong kanan kokuriklum mengamalkan gaya kepimpinan transformasional yang tinggi di sekolah menengah. Maka, mereka akan berinisiatif dalam melaksanakan tugasan mereka dengan rela hati dan berasa seronok untuk melaksanakan aktiviti sukan dan permainan untuk memenuhi keperluan dan matlamat sekolah.

Kajian ini menunjukkan dimensi karismatik mempunyai hubungan yang paling tinggi terhadap kepuasan guru penasihat kelab sukan dan permainan di sekolah menengah, ikuti oleh dimensi rangsangan intelek, motivasi inspirasi dan pertimbangan individu. Dapatan kajian ini berbeza dengan kajian Noraazian \& Khalip (2016) yang menunjukkan dimensi pertimbangan individu mempunyai hubungan yang paling tinggi dengan kepuasan kerja guru, diikuti oleh dimensi motivasi inspirasi, karismatik dan rangsangan intelektual untuk sekolah rendah di pinggir bandar. Perbezaan menunjukkan bahawa keutamaan dimensi-dimensi kepimpinan transformasional dalam mempengaruhi kepuasan kerja guru-guru di sekolah menengah yang kebanyakan di kawasan bandar dan luar bandar adalah berbeza dengan sekolah rendah di kawasan pinggir bandar. Namun begitu, kajian ini selari dengan kajian Arokiasamy, Abdullah \& Zohir (2016) yang mendapati dimensi karismatik menunjukkan hubungan yang paling tinggi terhadap kepuasan kerja guru dan dimensi pertimbangan individu mempunyai hubungan yang paling rendah dengan kepuasan kerja guru di sekolah rendah. Oleh itu, keutamaan terhadap urutan dimensi kepimpinan transformasional yang mempengaruhi kepuasan kerja guru-guru sekolah menengah dan sekolah rendah adalah hampir sama kecuali guru-guru sekolah rendah di kawasan pinggir bandar. Maka, Penolong kanan kokurikulum sekolah rendah yang bertugas di sekolah kawasan pinggir bandar, Penolong kanan kokurikulum sekolah menengah yang kebanyakan bertugas di sekolah kawasan bandar dan luar bandar dan Penolong kanan kokurikulum sekolah rendah yang bertugas di sekolah kawasan bandar dan luar bandar perlu memberikan perhatian kepada urutan keutamaan dimensi-dimensi kepimpinan transformasional semasa mengamalkan kepimpinan transformasional di sekolah rendah dan sekolah menengah.

\section{Kesimpulan}

Amalan kepimpinan transformasional yang tinggi oleh penolong kanan kokurikulum mampu memberikan kesan positif terhadap kepuasan kerja guru penasihat kelab sukan dan permainan dalam melaksanakan aktiviti sukan di sekolah menengah. Maka, kepimpinan transformasional dicadangkan kepada penolong kanan kokurikulum di sekolah menengah kerana gaya kepimpinanan ini memainkan peranan penting dalam memotivasikan guru-guru dan memberikan keselesaan kepada mereka untuk melaksanakan tanggungjawab dalam menjalankan aktiviti sukan di sekolah menengah bagi mencapai matlamat sekolah. Sementara itu, memberi perhatian dan penekanan kepada urutan keutamaan dimensi-dimensi kepimpinan transformasional mengikut kategori sekolah dan lokasi sekolah semasa mengamalkan kepimpinan transformasional juga dapat melancarkan lagi tugasan pengurusan penolong kanan kokurikulum di sekolah dan meningkatkan keefsienan pengurusan sukan di sekolah bagi mencapai matlamat sekolah.

\section{Penghargaan}

Penulis ingin mengucapkan terima kasih kepada Institut Pendidikan Guru, Kampus Tun Abdul Razak, Kota Samarahan atas bantuan dan maklumat yang diberikan untuk memastikan kejayaan kajian ini.

\section{Rujukan}

[1] Arokiasamy, A, R. A., Abdullah, A. G. K., Zohir, M. (2016). Transformational leadership of school principals and organizational health of primary school teachers in Malaysia. Social and Behavioral Sciences 229: 151157

[2] Avolio, B. J., \& Bass, B. M. (2004). Multifactor leadership questionnaire: Third edition manual and sampler set. Redwood City, CA: Mind Garden

[3] Babbie, E. R. (2001). The practice of social research (9 ed.). USA: Thompson Learning

[4] Cormarks, D. K. (2000). Leadership behaviors of secondary school principals and teachers satisfaction. Doctorial Thesis. University of New South Wales

[5] Creswell, J. W. (2012). Educational research: Planning, conducting and evaluating quantitative and qualitative research. U.S.A: Pearson Education, Inc

[6] Hoy, W. K. \& Miskel, C. G. (2013). Educational Administration: M c Graw- Hill International

[7] Idris, N. (2010). Penyelidikan Dalam Pendidikan. Kuala Lumpur: McGraw-Hill Education

[8] Kementerian Pendidikan Malaysia. (2011). Buku Panduan Pelaksanaan Dasar Satu Murid Satu Sukan (1M1S). Putrajaya: Bahagian Sukan

[9] Kementerian Pendidikan Malaysia. (2012). Laporan Tahunan 2012 Jemaah Nazir dan Jaminan Kualiti. Putrajaya: Jemaah Nazir dan Jaminan Kualiti

[10] Kouni, Z., Koutsoukos, M., \& Panta, D. (2018). Transformational leadership and job satisfaction: The case of secondary education teachers in Greece. Journal of Education and Training Studies, 6 (10): 158-168

[11] Lyonga, N, N, A. (2019). Principal's transformational leadership skills and teachers: Job 
satisfacation in secondary school in Meme division of Cameroon. European Journal of Education Studies. 6(1), 326-343

[12] Nazim, F. \& Mahmood, A. (2016). Principals' transformational and transactional leadership style and job satisfaction of college teachers. Journal of Education and Practice, 7(34): 18-22

[13] Noraazian \& Khalip. (2016). The impact of transformational leadership and teacher commitment in Malaysian public schools. International Journal of Academic Research in Business and Social Sciences, 6(11): 388-397

[14] Newman, W. (2003). Social research methods: qualitative and quantitative approaches (5th ed.). U.S.A: Pearson Education, Inc

[15] Pallant, J. (2013). SPSS survival manual: A step by step guide to data analysis using IBM SPSS. Berkshire: McGraw Hill

[16] Robbins, S. P., \& Judge, T. (2007). Organizational behavior. Upper Saddle River, N.J: Pearson/Prentice Hall.

[17] Tang, K. N. (2011). The effect of transformasional leadership on school culture in Male's Primary Schools Maldives. Online Journal of Social and Behavioral Sciences, 30: 2575-2580 